\section{$\underset{\substack{\text { hommes } \\ \text { \& migrations }}}{ }$}

\section{Hommes \& migrations}

Revue française de référence sur les dynamiques

migratoires

1328 | 2020

Les réfugiés dans l'impasse

\title{
La route des réfugiés est-elle une voie sans issue?
}

\author{
Isabelle Lendrevie
}

\section{CpenEdition \\ Journals}

\section{Édition électronique}

URL : https://journals.openedition.org/hommesmigrations/10625

DOI : 10.4000/hommesmigrations. 10625

ISSN : 2262-3353

\section{Éditeur}

Musée national de l'histoire de l'immigration

\section{Édition imprimée}

Date de publication : 1 janvier 2020

Pagination : 8

ISBN : 978-2-919040-49-0

ISSN : $1142-852 X$

\section{Référence électronique}

Isabelle Lendrevie, "La route des réfugiés est-elle une voie sans issue? », Hommes \& migrations [En ligne], 1328 | 2020, mis en ligne le 01 janvier 2020, consulté le 04 janvier 2023. URL : http:// journals.openedition.org/hommesmigrations/10625; DOI : https://doi.org/10.4000/ hommesmigrations. 10625 


\section{La route des réfugiés est-elle une voie sans issue?}

\section{Isabelle Lendrevie,}

avocate au Barreau de Seine-Saint-Denis, docteure en droit, membre de l'association Avocats pour la défense des droits des étrangers (ADDE'), de l'Institut international de droit d'expression et d'inspiration françaises $\left(\right.$ Idef $\left.^{2}\right)$ et de la commission «droits fondamentaux» de l'Association des juristes franco-colombiens ( $\left.\mathrm{AJFC}^{3}\right)$.

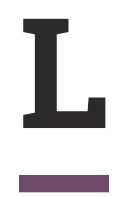

a question de la migration intéresse tout le monde aujourd'hui, les États, les instances internationales, les citoyens et les médias. Dans un monde globalisé où l'on assiste à la multiplication des conflits intra-étatiques et à une hausse des flux migratoires, il y a des migrations spontanées (estudiantines, économiques et culturelles) mais également forcées.

Il était important que des avocats soutenus par la commission, les Bâtonniers Frédéric Gabet (20192020) et Valérie Grimaud (2017-2018), Benoît Jouteux et Justine Mendes du Barreau de la Seine-Saint-Denis - département français particulièrement touché par ces questions migratoires et transculturelles puissent dialoguer et débattre avec d'autres acteurs du monde juridique (magistrats, universitaires et chercheurs), mais également avec des acteurs politiques, des universitaires d'autres disciplines (science politique, sociologie, anthropologie...) et des membres de la société civile (président d'ONG...), qu'ils viennent de France, d'autres pays européens (comme ici les Pays-Bas) ou d'autres rives du pourtour méditerranéen (ici la Tunisie et l'Égypte).

Le colloque international et pluridisciplinaire qui avait été organisé en janvier 2018 sur le même thème que ce numéro de la revue Hommes \& Migrations ("La route des réfugiés est-elle une voie sans issue?») visait à comprendre pourquoi, depuis 2015, les réfugiés ne pouvaient plus choisir leur route et leur pays d'installation, et pourquoi il y avait une crise de l'accueil et du droit plutôt qu'une «crise des réfugiés » au sein de cet espace européen si divers et de l'espace euro-méditerranéen.

Nos remerciements vont à Ryme Gasmi et Marion Dodier, avocates du Barreau de Seine-SaintDenis, à Béatrice Voss, avocate au Barreau des Hauts-de-Seine et présidente de la commission Libertés et droits de l'homme du Conseil national des Barreaux (CNB) ainsi qu'à Christiane Féral-Schuhl, sa présidente, qui, au cœur du mouvement actuel inédit de grève national des avocats de tous les barreaux français, rappellent que «les valeurs d'humanité et de respect de la dignité fondent le serment d'avocat».

Nos remerciements vont également à Faical Mkadem, étudiant à l'université Paris-8, Eve Shahshahani, avocate au Barreau de Paris et Carine Le Goff, avocate au Barreau de Seine-Saint-Denis.

1. Avocats pour la défense des droits des étrangers (ADDE) est une association française qui regroupe plus de 400 avocats français, spécialisés en droit des étrangers et souvent en droit d'asile, sur tout le territoire national.

2. L'Institut international de droit d'expression et d'inspiration françaises (Idef) et l'Association égyptienne des juristes francophones (AEJF) ont organisé, au siège de la ligue des États arabes au Caire en avril 2019, un colloque international sur les migrations : publication à venir en 2020.

3. L'Association des juristes franco-colombiens (AJFC), dont le président est l'avocat Manuel Bosque, organisera en 2020 une conférence sur « sur les migrations internationales comparaison France - Colombie » à la Maison de l'avocat et du droit de Bobigny et, en avril 2020, en Colombie, un colloque sur les migrations.

Pour plus de renseignements, voir le site de l'association https://www.juristesfrancocolombiens.com 